\title{
Abordagem da ecoinovação para a sustentabilidade das ferrovias no sul de Santa Catarina
}

\author{
The eco-innovation approach for the sustainability of \\ railroads in the South of the state of Santa Catarina
}

Ricardo Alves Colonettia

Cristina Keiko Yamaguchi ${ }^{b}$

Adriana Carvalho Pinto Vieirac

Júlio César Farias Zillid

\begin{abstract}
${ }^{a}$ Mestre em Desenvolvimento Socioeconômico pela Universidade do Extremo Sul Catarinense, Criciúma, SC, Brasil End. Eletrônico: ricardocolonetti@hotmail.com
\end{abstract}

${ }^{b}$ Docente do Programa de Pós-Graduação em Desenvolvimento Socioeconômico da Universidade do Extremo Sul Catarinense, Criciúma, SC, Brasil End. Eletrônico: criskyamaguchi@gmail.com

'Docente do Programa de Pós-Graduação em Desenvolvimento Socioeconômico da Universidade do Extremo Sul Catarinense, Criciúma, SC, Brasil End. Eletrônico: dricpvieira@gmail.com

${ }^{d}$ Mestre em Desenvolvimento Socioeconômico pela Universidade do Extremo Sul Catarinense, Criciúma, SC, Brasil End. Eletrônico: zilli42@hotmail.com

doi:10.18472/SustDeb.v7n3.2016.18271

Recebido em 25.03.2016

Aceito em 11.08.2016

ARTIGO - VARIA

\section{RESUMO}

As preocupações com o desenvolvimento sustentável levaram diversas organizações à introduzirem práticas ambientais em suas estratégias, resultando na produção e adoção das ecoinovações. Nesse sentido, este artigo buscou verificar como a ecoinovação pode contribuir para a sustentabilidade ferroviária no Sul de Santa Catarina. Tratou-se de uma pesquisa descritiva e bibliográfica com abordagem qualitativa e de um estudo de caso sobre o projeto do eco-vagão, desenvolvido pela Ferrovia Tereza Cristina. $O$ estudo permitiu associar a iniciativa ecoinovadora da empresa aos conceitos e classificações evidenciados na literatura. Os resultados demonstraram que o vagão de plástico contribuiu para a sustentabilidade da ferrovia, proporcionando ganhos financeiros e outros benefícios que impactaram diretamente no seu resultado; reduzindo o impacto ambiental ocasionado pela construção dos vagões e pela operação ferroviária; e contribuindo para ações junto à comunidade e colaboradores.

Palavras-chave: Ferrovia. Ecoinovação. Eco-vagão. 


\begin{abstract}
The article seeks to find how eco-innovation can contribute to the sustainability of the railroads operating in the Southern part of the state of Santa Catarina. It displays the findings of a descriptive and bibliographical research, with a qualitative approach and based on a case study. A questionnaire was applied to the project and transportation maintenance manager of the railroad company Ferrovia Tereza Cristina S.A. The manufacturing and the use of the eco-wagon caused several benefits in the economic, environmental and social fields. There was a 15 percent reduction of operational costs; the useful life of the eco-wagon tripled; cargo transportation capacity increased by 1.5 tons per car; the time for cargo unloading was shortened from five to three minutes; the level of noise during unloading was reduced by the use of recycled materials; the risk of contamination by leakage during transportation was reduced; the need to cut down two trees per wagon was eliminated by the use of recycled materials.
\end{abstract}

Keywords: Railway. Eco-innovation. Eco-wagon.

\title{
1 INTRODUÇÃO
}

Embora as discussões envolvendo a preocupação com o meio ambiente sejam anteriores à década de 1970, diversos estudos apontam a realização da Conferência das Nações Unidas sobre o Meio Ambiente Humano, organizada em Estocolmo, pela Organização das Nações Unidas (ONU), em 1972, como o marco dos debates sobre desenvolvimento sustentável (BARBIERI et al., 2010).

Em 1987, a Comissão Mundial sobre o Meio Ambiente e o Desenvolvimento, também organizada pela ONU, publicou o documento intitulado Nosso Futuro Comum, que definiu desenvolvimento sustentável como "aquele que atende às necessidades do presente sem comprometer a possibilidade de as gerações futuras atenderem a[s] suas próprias necessidades" (COMISSÃO MUNDIAL SOBRE MEIO AMBIENTE E DESENVOLVIMENTO, 1991, p. 46).

Posteriormente, em 1992, realizou-se no Rio de Janeiro, a Conferência das Nações Unidas sobre o Meio Ambiente e o Desenvolvimento (Rio-92), que resultou na criação da Agenda 21. Este documento, 20 anos após a Conferência de Estocolmo, avançou nos debates sobre o desenvolvimento sustentável, incluindo temas relacionados ao desenvolvimento social, ambiental e econômico, como a pobreza, a dívida externa dos países em desenvolvimento, os padrões mundiais de produção e consumo, as pressões demográficas e a economia internacional (BRASIL, 1995).

Em consonância ao novo tratamento atribuído ao desenvolvimento sustentável, John Elkington cunhou o termo "triple bottom line", segundo o qual, as organizações deveriam medir seus resultados, a partir do equilíbrio entre três domínios: pessoas, planeta e lucro (ELKINGTON, 2004).

Esse movimento contribuiu para que, a partir do fim da década de 1980 e ao decorrer da década de 1990, a gestão ambiental e a introdução de inovações voltadas à sustentabilidade passassem a integrar a estratégia de várias organizações ao redor do mundo (ARUNDEL; KEMP; PARTO, 2007).

Enquanto as lideranças mundiais enxergavam a ecoinovação como um elemento importante de resposta às preocupações contemporâneas, como as alterações climáticas, a segurança energética e a excessiva utilização dos recursos naturais; as organizações passaram a enxergá-la como uma potencial fonte de vantagem competitiva, dado o rápido crescimento e a aceitação dos bens e serviços considerados "verdes" (ORGANISATION FOR ECONOMIC CO-OPERATION AND DEVELOPMENT, 2011).

Diante desse contexto, o objetivo deste artigo foi verificar como a ecoinovação pode contribuir para a sustentabilidade ferroviária no Sul de Santa Catarina. Para alcançar o objetivo proposto, realizou-se um estudo de caso, junto à Ferrovia Tereza Cristina S.A., abordando o projeto do vagão de plástico, denominado eco-vagão.

$\mathrm{O}$ artigo foi estruturado em cinco seções, incluindo a presente, que se dedica à introdução. A segunda seção apresenta o referencial teórico. A terceira seção aborda a metodologia. A quarta seção apresenta o estudo de caso e sua discussão. Por fim, a quinta seção é destinada às considerações finais. 


\section{REFERENCIAL TEÓRICO}

Este capítulo apresenta o referencial teórico, abordando conceitos, classificações e estratégias referentes à ecoinovação, bem como alguns estudos recentes sobre o tema, em âmbito nacional. Ainda aborda as características da inovação no setor ferroviário.

\subsection{ECOINOVAÇÃO: INOVAÇÃO E SUSTENTABILIDADE}

Para Schumpeter (1982), considerado o precursor dos debates sobre inovação, o desenvolvimento econômico é resultado da ação do "empresário inovador", que se utiliza dos meios existentes para realizar "novas combinações". Essas novas combinações são as inovações que, nas palavras do autor, podem ser:

1) Introdução de um novo bem [...] ou de uma nova qualidade de um bem. 2) Introdução de um novo método de produção [...] [ou de uma] nova maneira de manejar comercialmente uma mercadoria. 3) Abertura de um novo mercado [...]. 4) Conquista de uma nova fonte de oferta de matérias-primas ou de bens semimanufaturados [...]. 5) Estabelecimento de uma nova organização de qualquer indústria [...] (SCHUMPETER, 1982, p. 48).

A partir do pensamento de Schumpeter, diversos autores desenvolveram conceitos para tratar a inovação. Conceição (2000), por exemplo, relacionou inovação à tecnologia, sintetizando-a como o conhecimento técnico empregado na produção de bens e serviços. Por sua vez, a Lei n. 10.973/2004 (Lei da Inovação), apresentou um conceito mais abrangente, que envolveu o aspecto social, definindo inovação como a inserção de novidades e aperfeiçoamentos em produtos, processos e serviços, nos ambientes produtivo e social (BRASIL, 2004).

Recentemente, em torno dos debates sobre o desenvolvimento sustentável e as preocupações com a preservação do meio ambiente, emergiu o conceito da inovação destinada à redução dos impactos ambientais (BARBIERI et al., 2010) que, pode assumir diversas nomenclaturas, como, por exemplo: "inovação ambiental", "ecoinovação", "inovação sustentável" ou "inovação verde" (PINSKY et al., 2015).

Segundo Porter e Linde (1995), a inovação ambiental é aquela que propicia utilizar os insumos (energia, mão de obra e matéria-prima) de forma mais eficiente, contribuindo para a redução do impacto ambiental.

O termo "ecoinovação" é atribuído aos autores Fussler e James, no livro Driving eco-innovation, publicado em 1996 (COELHO, 2015). Na concepção de Fussler e James (1996), a ecoinovação deve agregar valor ao negócio e aos clientes, diminuindo, significativamente, os impactos ambientais.

Rennings (2000) corrobora este pensamento, evidenciando que a ecoinovação, ao introduzir conceitos voltados à proteção ambiental, mudou o foco da inovação tecnológica que visava apenas a eficiência econômica dos sistemas produtivos.

Kemp e Pearson (2007), baseados no Manual de Oslo, trouxeram um conceito mais amplo de ecoinovação, considerando o ciclo de vida da iniciativa inovadora e a redução do impacto ambiental negativo, em comparação às alternativas existentes. Segundo os autores,

Ecoinovação é a produção, assimilação ou exploração de um produto, processo de produção, serviço ou método de gestão ou de negócio que é novo para a organização [...] e que resulta, ao longo do seu ciclo de vida, na redução do risco ambiental, poluição e outros impactos negativos do uso de recursos (incluindo o uso de energia) se comparado com alternativas correspondentes (KEMP; PEARSON, 2007, p. 7, grifo dos autores).

Esse pensamento também é difundido por Reid e Miedzinski (2008), para os quais, toda a inovação que, a partir da perspectiva do ciclo de vida do produto ou serviço, em qualquer parte do processo, envolva menor intensidade do uso de recursos e energia, contribuindo para a redução dos impactos ambientais, pode ser considerada uma inovação ambiental ou ecoinovação.

Seguindo a mesma linha de entendimento, a Organização para a Cooperação e Desenvolvimento Econômico (OECD), classificou ecoinovação como qualquer forma de inovação (bens, serviços, 
processos fabris ou modelos de negócios) que reduza os impactos ambientais e otimize a utilização de recursos ao longo do ciclo de vida das atividades relacionadas (ORGANISATION FOR ECONOMIC COOPERATION AND DEVELOPMENT, 2011).

\subsection{CLASSIFICAÇÕES E TIPOLOGIA PARA ECOINOVAÇÕES}

Devido à complexidade da mudança técnica e à grande quantidade de inovações introduzidas anualmente, Freeman e Perez (1988) sugeriram uma taxonomia para classificá-las. Segundo os autores, as inovações podem ser classificadas como inovação incremental, inovação radical, novos sistemas de tecnologia e mudanças do paradigma técnico-econômico.

As inovações incrementais são mais frequentes e estão relacionadas às melhorias introduzidas em produtos e processos, resultando, geralmente, em ganhos como aumento de produtividade, melhoria na qualidade de um produto ou serviço ou adequação a uma exigência legal ou mercadológica. As inovações radicais são menos frequentes e surgem de modo a alterar um padrão, podendo descontinuar o anterior (causar uma ruptura) e levar ao surgimento de novas indústrias e serviços (FREEMAN; PEREZ, 1988).

Os novos sistemas de tecnologia são resultado da combinação entre inovações radicais, incrementais e organizacionais (de gestão), ocasionando profundas alterações em diversos ramos da economia, dando origem a novos setores. Por fim, as mudanças do paradigma técnico-econômico afetam toda a economia, combinando diversas inovações radicais e incrementais e incorporando uma série de novos sistemas de tecnologia, dando origem a diversos novos produtos, serviços e indústrias e causando uma "revolução tecnológica" (FREEMAN; PEREZ, 1988).

Segundo Rennings (2000), considerando a sua natureza, uma ecoinovação pode ser: a) tecnológica curativa (que visa reparar danos ambientais) ou preventiva (que busca preveni-los); b) organizacional - que envolve a adoção de instrumentos de gestão; c) social - que envolve a alteração de hábitos de consumo da população ("consumo sustentável"); ou d) institucional - incluindo novos arranjos institucionais, métodos de avaliação e regimes de governança global e a criação de redes e agências voltadas à sustentabilidade.

Kemp e Pearson (2007), também propõem uma classificação para os tipos de ecoinovação, a saber: a) tecnologias ambientais - incluindo tecnologias para tratamento de água e resíduos, monitoramento ambiental e produção limpa; b) inovação organizacional para o meio ambiente - incluindo a introdução de novos métodos e sistemas de gestão ambiental; c) inovação de produtos e serviços focada em benefícios ambientais; d) inovação de sistema verde - incluindo sistemas alternativos de produção e consumo e novos materiais.

Bleischwitz et al. (2009), por sua vez, agrupam as ecoinovações em três categorias principais: a) processo - introdução de algo novo ou de alguma melhoria nos processos de produção, entrega ou de gestão (inovação organizacional); b) produto - introdução de um novo produto ou serviço ou melhoria significativa em um produto ou serviço já existente, de forma a minimizar o seu impacto ambiental; e c) sistemas de inovação - sistemas tecnológicos e tecnologias radicais e disruptivas, que alteram as condições de mercado.

\subsection{ESTRATÉGIAS DE ECOINOVAÇÃO}

Para Nelson e Winter (1982) a inovação está relacionada à competição que, por sua vez, define os "vencedores" e os "perdedores". Dessa forma, as firmas inovam buscando o lucro e aquelas que não o fazem correm o risco de saírem perdedoras. Nesse sentido, Bessant e Tidd (2009) enfatizam a relevância da inovação para que uma organização consiga gerar ou sustentar uma posição de vantagem competitiva ou, simplesmente, sobreviva ao ambiente concorrencial imposto pelo mercado.

Entretanto, Rennings (2000) esclarece que as ecoinovações podem ser desenvolvidas tanto por organizações com fins lucrativos, quanto pelas que não possuem tais fins, podendo, desse modo, 
serem ou não comercializadas. Entre as motivações para o desenvolvimento de uma ecoinovação, o autor relata a influência da tecnologia, do mercado e da legislação. Desse modo, uma ecoinovação pode ser "empurrada" pela tecnologia ou pela legislação ou, ainda, "puxada" pelo mercado.

Barbieri et al. (2010), em seu trabalho de cunho teórico, tendo como base a teoria institucional, defendem que as práticas de inovação sustentável, por parte das organizações, podem emergir da necessidade de internalizar aquilo que é bem visto (melhores práticas) pela sociedade e demais stakeholders, como estratégia organizacional que vise a legitimidade, e não como uma iniciativa proveniente da simples vontade de ecoinovar.

Com relação ao posicionamento, Freeman e Soete (2008) classificam as estratégias de inovação das firmas em ofensiva, defensiva, imitativa, dependente, tradicional e oportunista.

De forma resumida, a estratégia ofensiva enfatiza a busca pela liderança tecnológica ou de mercado, enquanto a defensiva dá ênfase à manutenção da concorrência. Em ambas as estratégias há investimento intensivo em pesquisa e desenvolvimento, porém, enquanto na estratégia ofensiva há a busca pelo novo e a preocupação com a proteção (patentes), na defensiva as firmas são avessas ao risco e buscam apenas seguir os líderes (FREEMAN; SOETE, 2008).

Por sua vez, nas estratégias imitativa, dependente, tradicional e oportunista, não há investimento em pesquisa e desenvolvimento. Na estratégia imitativa as firmas buscam competir pelo posicionamento em custos, adquirindo tecnologia, licenças e know-how; na dependente, estabelecem relações com outras firmas e seu investimento se dá em produção e marketing; na oportunista, buscam atender nichos de mercado; e na tradicional, devido a um cenário próximo da concorrência perfeita, não há estímulo à inovação, sendo as tecnologias e técnicas de conhecimento comum (FREEMAN; SOETE, 2008).

Ainda com relação à estratégia de ecoinovação, no que concerne a sua adoção e desenvolvimento, Kemp e Pearson (2007) relatam que as empresas podem ser classificadas como ecoinovadoras estratégicas, ecoadotantes estratégicas, ecoinovadoras passivas e não ecoinovadoras.

As ecoinovadoras estratégicas são as firmas que desenvolvem ecoinovações voltadas ao mercado; as ecoadotantes estratégicas são aquelas que implementam ecoinovações, sejam elas adquiridas no mercado ou desenvolvidas internamente; as ecoinovadoras passivas são aquelas que não possuem estratégia de inovação, mas que acabam desenvolvendo processos ou produtos que resultam em ganhos ambientais; e, por fim, as não ecoinovadoras são aquelas que não desenvolvem atividades ou adquirem soluções de caráter ecoinovador (KEMP; PEARSON, 2007).

\subsection{APLICAÇÃO DA ECOINOVAÇÃO NO CENÁRIO NACIONAL}

Os trabalhos acadêmicos envolvendo a realização de práticas ecoinovadoras, no âmbito empresarial e em nível nacional, abrangem diversas indústrias e setores econômicos, como, por exemplo: cerâmica (FARIAS et al., 2012); eletroeletrônica (BRITO; AGUIAR, 2014); papel e celulose (MAÇANEIRO et al., 2014); sucroenergética (SANTOS; BASSO; KIMURA, 2014); reciclagem (COELHO, 2015); e metalmecânica (THEIS; SCHREIBER, 2015). Contudo, para Pinsky et al. (2015), embora tenha crescido nos últimos anos, a produção acadêmica brasileira sobre o tema ainda é incipiente.

Farias et al. (2012) verificaram a introdução da ecoinovação por uma empresa do segmento de cerâmica vermelha. Tratou-se da incorporação de uma ecoinovação ao processo produtivo, com a substituição do forno, que resultou na otimização do processo de queima. Como resultado desta incorporação, os autores verificaram ganhos econômicos (redução de custos e maior qualidade do produto), sociais (melhores condições de trabalho) e ambientais (aumento da eficiência energética e menor utilização de recursos).

Brito e Aguiar (2014) desenvolveram um estudo junto a uma empresa multinacional da indústria eletroeletrônica. Segundo o estudo, a empresa adota uma postura ecoinovadora, atribuindo metas 
de sustentabilidade e monitorando o seu desempenho social e ambiental; e dedica investimentos ao desenvolvimento de "produtos verdes". Os autores ainda verificaram a prevalência das abordagens de estratégias ambientais referentes à eficiência energética (em seus produtos) e à cadeia de suprimento verde (logística reversa e sustentabilidade em fornecedores).

Maçaneiro et al. (2014) abordaram a ecoinovação na cadeia produtiva da indústria do papel e celulose, analisando uma amostra composta por 117 empresas, em todo o Brasil. Os autores verificaram que as empresas localizadas no início da referida cadeia produtiva possuem atuação mais proativa em relação à ecoinovação, contrariando a literatura que afirma que as empresas inseridas no fim da cadeia estão mais propensas às práticas ecoinovadoras, por estarem mais próximas ao cliente final. Para os autores, o melhor desempenho das empresas do início da cadeia pode ser explicado devido ao fato de serem as que geram maior impacto ambiental e, por conseguinte, sofrem maior pressão da legislação; e por possuírem maior porte (médias e grandes) e atuarem no mercado internacional.

Santos, Basso e Kimura (2014), realizaram seu estudo sobre ecoinovação, junto a uma empresa sucroenergética, localizada no interior de estado de São Paulo. Foram analisadas duas unidades fabris da empresa, que realizam atividades de plantio de cana-de-açúcar, produção de açúcar e etanol e geração de energia elétrica. Como resultado, os autores verificaram que a empresa possui um posicionamento reativo quanto à ecoinovação, buscando adequação à legislação. Ademais, informaram dificuldade em aprofundar a análise devido à falta de informações nos documentos verificados.

Coelho (2015) desenvolveu seu estudo em uma empresa de reciclagem de papel e fabricação de telas de fibras vegetal, localizada em Manaus. Como resultado, verificou que a empresa inovou na fabricação de produtos, utilizando insumos amazônicos (fibra da juta e papel de guaraná), e nos processos industriais, com a readequação das máquinas aos novos insumos. Para o autor, a organização em questão pode ser considerada ecoinovadora estratégica, estando em busca de novos mercados e inovando em produtos e processos. Ademais, destaca que as ecoinovações adotadas contribuíram para melhores resultados da empresa, redução do impacto ambiental e trouxeram benefícios sociais.

Theis e Schreiber (2015), em estudo realizado junto a uma amostra de empresas da indústria metalmecânica do Rio Grande do Sul, buscaram identificar como as práticas ambientais se inserem nas atividades de inovação de produtos e processos. Os resultados obtidos apontaram para o fato das empresas atuarem de forma reativa, de modo a atender aos dispositivos legais, limitando a inserção das práticas ambientais aos processos industriais. Com relação aos produtos, geralmente, há a adaptação do já existente, visando redução de custo ou melhoria no desempenho, porém, isto não significa a substituição de matérias-primas, com a finalidade de reduzir o impacto ambiental.

Em suma, estes estudos evidenciam dois comportamentos distintos entre as empresas que adotam práticas ecoinovadoras: proativo e reativo. O comportamento proativo, geralmente, incorpora a ecoinovação como estratégia, desenvolvendo-a em busca de melhores resultados. Por sua vez, o reativo faz uso da ecoinovação no intuito de cumprir uma exigência legal, social ou mercadológica.

\subsection{CARATERÍSTICAS DA (ECO)INOVAÇÃO NA ATIVIDADE FERROVIÁRIA}

A história das ferrovias está diretamente relacionada à inovação. Em um primeiro momento, com a introdução do motor a vapor, as estradas de ferro apresentaram uma nova alternativa de transporte (inovação radical). Posteriormente, com o passar dos anos e os avanços científicos e tecnológicos, diversas alterações (inovações incrementais) foram introduzidas aos processos de operação (sistemas de comunicação e monitoramento), à via permanente (trilhos e dormentes) e ao material rodante (locomotivas e vagões) (VAZ, 2008).

Segundo Vaz (2008), tecnologicamente, a atividade ferroviária é considerada madura e consolidada, existindo assim, menos espaço para as inovações radicais e mais espaço para as inovações incrementais. Pitassi (2011, p. 246-247) corrobora a afirmação ao argumentar que, no setor ferroviário, "a taxa de mudança tecnológica é baixa e [...] o ciclo de vida do produto é longo". 
Com relação às fontes, as inovações da indústria ferroviária estão centralizadas nos fornecedores que dominam as tecnologias globais. De modo geral, as empresas ferroviárias brasileiras são usuárias seguidoras (que adotam as inovações algum tempo após as líderes globais) e possuem postura estratégica, predominantemente, defensiva (VAZ, 2008).

Porém, existem casos nos quais o desenvolvimento da inovação está internalizado nas empresas concessionárias do transporte ferroviário sendo, geralmente, conduzido com recursos próprios, pelas áreas de engenharia, tecnologia da informação ou manutenção de vagões e locomotivas (VAZ, 2008; PITASSI, 2011) e visando, principalmente, ganhos de produtividade e redução de custos (FISHLOW, 1966; SMITH, 2001).

No que concerne ao desenvolvimento da inovação, Vaz (2008) argumenta que os esforços do setor estão centrados na melhoria operacional, redução de custos e ampliação dos serviços prestados, estando, desse modo, limitados à pequenos avanços incrementais em equipamentos e processos, que não contribuem sobremaneira à indústria ferroviária nacional. Nesse cenário, a inovação é vista como uma forma de obter vantagem competitiva ou solucionar problemas imediatos, e não como uma alternativa de crescimento futuro ou de obtenção de uma posição competitiva única.

No que diz respeito à competitividade, Vaz (2008) relata a característica "monopolista" da atividade ferroviária, na qual as operadoras possuem área de atuação definida pela malha concessionada, não existindo concorrência (salvo a utilização de outros meios de transporte, como o rodoviário). Desse modo, o cliente se torna cativo e, se optar pelo transporte ferroviário, deverá contratar a operadora da malha. Tal situação pode trazer "comodidade" à operadora que, por sua vez, não vê a necessidade de investir em atividades de pesquisa ou aquisição de novas tecnologias.

Com relação à ecoinovação na indústria ferroviária, percebe-se maior inclinação para investimentos em tecnologias voltadas à eficiência energética que, ao mesmo tempo em que reduzem o impacto ambiental, também contribuem para a melhoria da produtividade e para a redução de custos (VAZ, 2008). Entretanto, existem outras iniciativas como o desenvolvimento de dormentes com material alternativo, como a madeira plástica (PARENTE; PINHEIRO, 2008) e a instalação de pisos de borracha reciclada nas passagens de nível (FREITAS, 2010).

\section{MATERIAIS E MÉTODOS}

Quanto aos seus objetivos, a presente pesquisa se caracterizou como descritiva. As pesquisas descritivas são aquelas que têm por objetivo descrever as características de um determinado objeto de estudo ou estabelecer relações entre variáveis, por meio da utilização de técnicas padronizadas de coleta de dados como, por exemplo, o questionário (GIL, 2002).

Quanto aos meios de investigação, tratou-se de uma pesquisa bibliográfica e de um estudo de caso. "A pesquisa bibliográfica é um apanhado geral sobre os principais trabalhos já realizados, revestidos de importância, por serem capazes de fornecer dados atuais e relevantes relacionados com o tema" (LAKATOS; MARCONI, 2003, p. 158).

Por sua vez, o estudo de caso é o procedimento que "consiste no estudo [...] de um ou poucos objetos [no intuito de] proporcionar uma visão global do problema ou de identificar possíveis fatores que o influenciam ou são por ele influenciados" (GIL, 2002, p. 54-55). Nesse sentido, a Ferrovia Tereza Cristina S.A. foi a empresa escolhida para a realização do estudo de caso.

Desde 1997, a Ferrovia Tereza Cristina S.A. (FTC), é a concessionária da malha Tereza Cristina, localizada no Sul de Santa Catarina. A ferrovia possui 164 quilômetros de extensão e se destaca pelo transporte de carvão, das minas do Sul Catarinense até o Complexo Termoelétrico Jorge Lacerda, no município de Capivari de Baixo. Além do carvão, a FTC também transporta contêineres entre um terminal intermodal localizado em Criciúma e o Porto de Imbituba (FERROVIA TEREZA CRISTINA, 2015a). 
Primeiramente, o website da empresa foi acessado, permitindo verificar que a FTC incorpora o compromisso socioambiental e a sustentabilidade à sua política corporativa. A empresa realiza diversas ações sociais, no intuito de contribuir com a comunidade e com os seus colaboradores. Entre as ações voltadas ao cuidado e preservação ambiental, desenvolvidas internamente, estão a coleta seletiva, o gerenciamento de resíduos e efluentes, a implementação do programa de gestão ambiental e a construção do eco-vagão. (FERROVIA TEREZA CRISTINA, 2015b). Por aliar práticas de inovação e sustentabilidade, a que atribui o conceito de ecoinovação, o eco-vagão foi selecionado para este estudo.

Em seguida, após contato prévio, um questionário semiestruturado foi encaminhado, via e-mail, ao gerente de manutenção e transporte da ferrovia. O referido instrumento de coleta de dados foi elaborado contendo questões abertas e fechadas e estruturado com o objetivo de identificar as características da ecoinovação e os impactos causados pela adoção do eco-vagão, nas atividades da empresa.

Posteriormente, após o tratamento dos dados coletados, realizou-se uma visita ao Centro de Controle Operacional (CCO) da FTC, que possibilitou conversar pessoalmente com o gerente, esclarecer as dúvidas remanescentes e observar algumas unidades do eco-vagão.

\section{ESTUDO DE CASO: ECO-VAGÃO}

Embora reconheça a importância, a Ferrovia Tereza Cristina não possui área responsável pela gestão da inovação e, por isso, os projetos inovadores são conduzidos, internamente, pelos setores de tecnologia de informação ou manutenção.

O vagão de plástico ou eco-vagão consiste na utilização de polietileno de alta densidade reciclado, para revestir as laterais e o assoalho dos vagões $\mathrm{GHD}^{1}$, destinados ao transporte de carvão, sendo idealizado e desenvolvido pela equipe de manutenção da empresa, com o objetivo de aliar conceitos de sustentabilidade e reduzir os custos de manutenção.

Buscando novas formas para construir os vagões GHD, a equipe estudou diversos materiais alternativos à madeira de lei (angelim, canela ou cedro), como, por exemplo, eucalipto, laminados, aço e fibra de vidro. Os materiais se apresentaram inviáveis, seja pelo custo elevado ou pela baixa durabilidade e confiabilidade. Porém, em uma feira do setor ferroviário, o gerente da equipe conheceu uma empresa que fabricava itens a partir da utilização do polietileno de alta densidade reciclado. Nesse momento, surgiu a ideia de utilizar o referido material para a fabricação dos vagões.

Entre os primeiros estudos e o desenvolvimento do protótipo foram cinco anos, sendo o projeto financiado com recursos próprios. O primeiro eco-vagão entrou em circulação em dezembro de 2005 e, após um ano de testes, sua avaliação apresentou resultados positivos, ocasionando a implementação definitiva do projeto.

Desse modo, a partir de 2007, a empresa passou a fabricar apenas eco-vagões. Em 2015, a FTC possuía 250 vagões GHD em operação, sendo 180 eco-vagões e 70 convencionais. Até 2019, a empresa pretende substituir todos os vagões GHD convencionais por eco-vagões.

A Figura 1 apresenta a imagem do eco-vagão e do vagão convencional. 


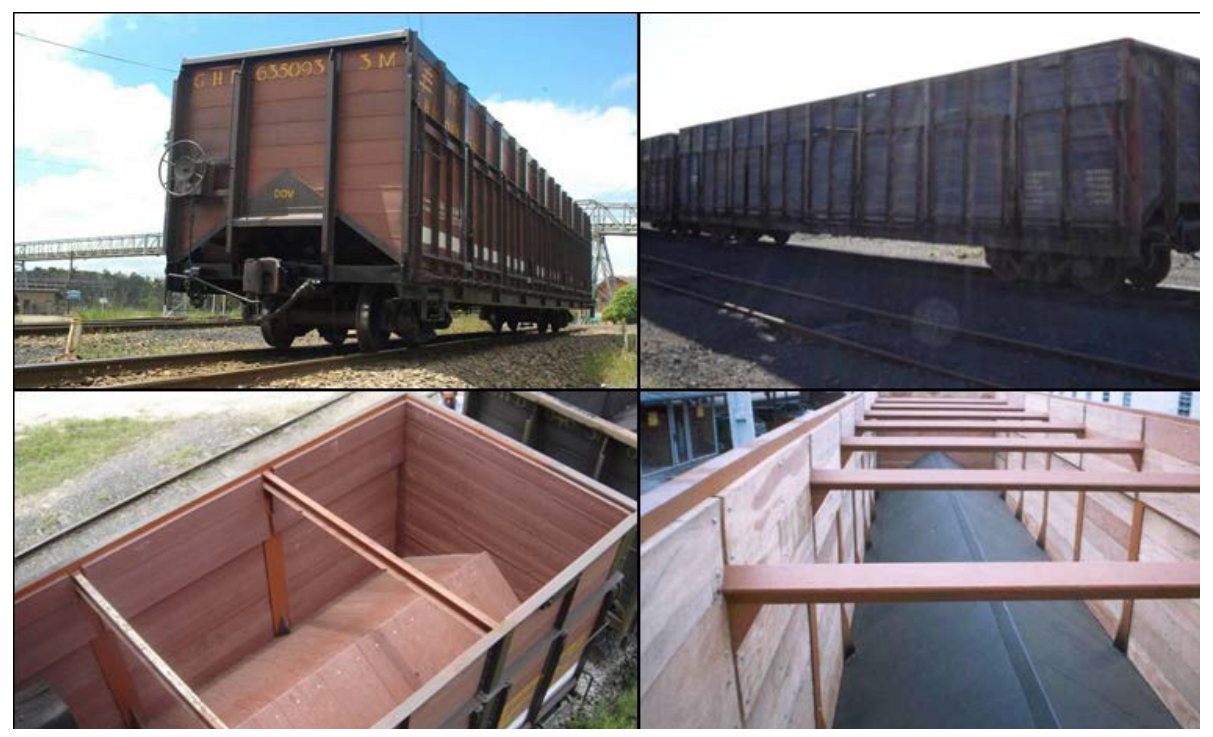

Figura 1 - Comparação: eco-vagão x vagão convencional

Fonte: Acervo da Ferrovia Tereza Cristina.

Quando questionado acerca do alcance do objetivo inicial do projeto, que era reduzir o impacto ambiental e os custos de manutenção, o gerente informou que o projeto não apenas cumpriu o objetivo proposto, como também superou as expectativas, uma vez que, obteve ganhos adicionais com o aumento de produtividade e de segurança no processo operacional. Esses ganhos, por sua vez, levaram a novos ganhos financeiros e ambientais.

Outro ponto ressaltado na pesquisa, foi que após algum tempo da implementação do projeto, e com mais eco-vagões em operação, percebeu-se que a frota apresentou um melhor visual, em decorrência do fato do plástico manter uma boa aparência mesmo com a ação do tempo.

O vagão GHD convencional tem as laterais construídas com madeira de lei e o assoalho revestido com chapas de aço, embora alguns apresentem o interior em madeira. No eco-vagão, a madeira e o aço são substituídos por placas de madeira plástica, obtidas por meio da reciclagem de materiais descartados como lixo e resíduos industriais. Segundo o relato do gerente, além de utilizar material reciclado, que demoraria cerca de 300 anos para se decompor, a construção do eco-vagão ainda descarta o uso de duas árvores adultas, ou seja, aquelas em condições de corte, com diâmetro médio de 90 centímetros.

A Figura 2 apresenta algumas das etapas da montagem do eco-vagão.

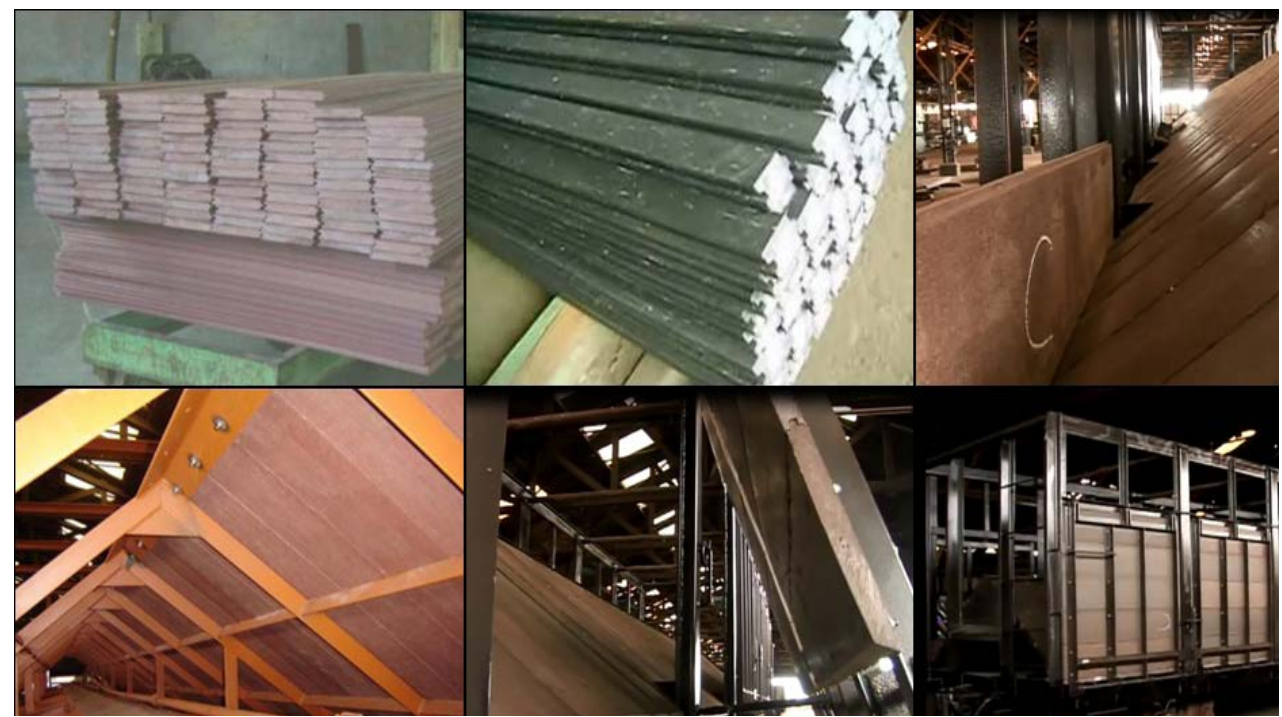

Figura 1 - Comparação: eco-vagão x vagão convencional

Fonte: Acervo da Ferrovia Tereza Cristina. 
Com o passar dos anos, seja pela característica do transporte ou pela ação do tempo, as tábuas do vagão convencional acabam se afastando, ocasionando frestas ou rompimentos, pelos quais podem ocorrer a perda do carvão transportado ou o vazamento dos finos de carvão² que, por sua vez, pode acarretar na contaminação do lastro da ferrovia. A ação do tempo ainda pode causar oxidação na estrutura metálica do vagão. Tanto as frestas ou rompimento das tábuas, quanto a oxidação, requerem reparos na estrutura do vagão, envolvendo custos e mantendo-o inativo durante o tempo de reparo.

Por sua vez, o eco-vagão é mais resistente à ação do tempo e às especificidades do transporte, possuindo uma estrutura protegida da oxidação e que proporciona uma melhor vedação e encaixe dos componentes, uma vez que, o plástico apresenta maior estanqueidade e não absorve a água. Por ter melhor vedação, dificilmente haverá perda do carvão transportado por frestas ou similares, aumentando a confiabilidade da frota. O eco-vagão ainda permite maior disponibilidade do vagão, pois necessita de menos reparos, em comparação ao convencional, fato que também leva à redução dos custos de manutenção.

Os principais problemas estruturais do vagão convencional são apresentados na Figura 3.

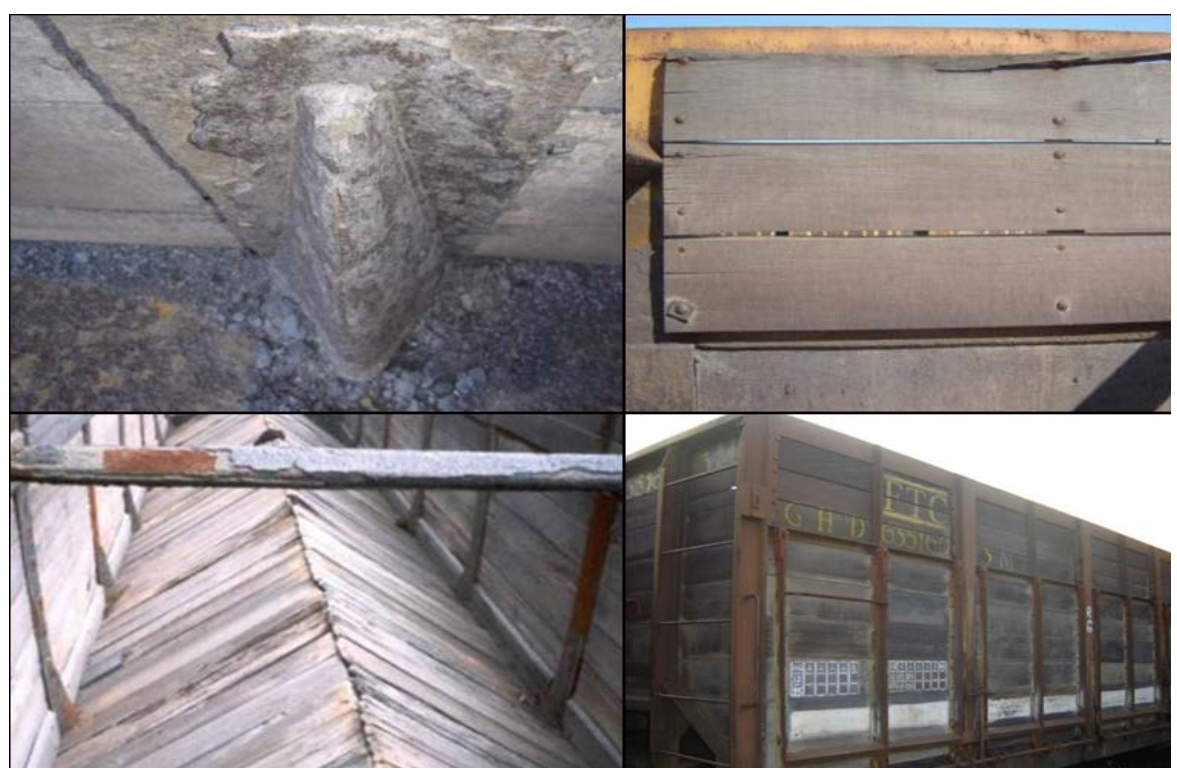

Figura 3 - Principais problemas apresentados pelo vagão convencional

Fonte: Acervo da Ferrovia Tereza Cristina.

Conforme publicação da Confederação Nacional do Transporte (2013), o tempo estimado para reposição dos vagões ferroviários é de aproximadamente 10 anos. A vida útil do eco-vagão é de 30 anos, enquanto a do vagão convencional, de madeira e aço, é de 12 anos. Então, o eco-vagão tem vida útil quase três vezes maior, se comparado ao vagão convencional.

Os materiais utilizados na construção de vagões, assim como suas respectivas vidas úteis, são apresentados na Tabela 1.

Tabela 1 - Vida útil dos materiais utilizados na construção dos vagões

\begin{tabular}{lc}
\hline \multicolumn{1}{c}{ Material } & Vida útil (anos) \\
\hline Plástico reciclado & 30 \\
Madeira de lei & 12 \\
Madeirite com fibra & 12 \\
Chapa de aço & 10 \\
Compensado naval & 5 \\
Eucalipto & 4 \\
\hline
\end{tabular}

Fonte: Dados da pesquisa (2015). 
O custo do projeto do eco-vagão é $5 \%$ maior, em comparação ao projeto do vagão convencional, porém, considerando a relação custo-benefício (a vida útil triplicada, os benefícios ambientais e a redução de custos, principalmente, com manutenção), tornou-se viável.

O eco-vagão não demanda pintura, pois o plástico reciclado já vem pigmentado e descarta a compra, manuseio e estoque da madeira (pelo período de sete meses, para secagem), reduzindo também custos de estoque e insumos de produção. Ademais, o custo com a manutenção anual do vagão ficou $15 \%$ menor, mesmo índice de redução verificado na revisão hexanual. Nesse percentual de redução de custos estão incluídos: combustível, imobilização, manobras, energia elétrica, manutenção de máquinas e equipamentos de marcenaria, pintura dos vagões e substituição do revestimento de madeira e aço.

Com relação à produtividade, percebeu-se o aumento de 1,5 tonelada de carga útil por vagão: o vagão convencional pesa 22 toneladas, enquanto o eco-vagão pesa 20,5 toneladas. Essa redução no peso do vagão, permitiu aumentar a tonelagem transportada de 59,5 para 61 toneladas, elevando, consequentemente, a produtividade.

Na operação de descarga do carvão, o eco-vagão permitiu que o mineral deslizasse com maior facilidade, devido ao baixo coeficiente de atrito do material (plástico). Nos vagões convencionais, o carvão adere ao revestimento de madeira e aço, necessitando utilizar um equipamento para vibrar as paredes do vagão e, assim, desprender o carvão. Com os eco-vagões, dadas as suas características, dificilmente este equipamento é utilizado, ocasionando a redução no custo da operação e também dos ruídos decorrentes dela.

Ainda com relação ao baixo coeficiente de atrito e a maior facilidade na descarga dos eco-vagões, mensurando o tempo da operação, verificou-se um ganho de aproximadamente dois minutos por vagão: enquanto nos vagões convencionais, de madeira e aço, a operação demora, em média, cinco minutos, nos eco-vagões a média de tempo caiu para três minutos. Para fins de cálculo total, registra-se que, em média, as composições trafegam com 40 vagões.

\section{DISCUSSÃO DOS RESULTADOS}

Em consonância à literatura, seguindo a classificação de Schumpeter (1982), o eco-vagão pode ser considerado a "introdução de uma nova qualidade em um bem", uma vez que, em comparação ao vagão convencional, não perdeu as suas características.

Nesse caso, houve apenas a mudança no material utilizado para sua construção, permitindo, conforme Freeman e Perez (1988), classificá-lo como uma inovação incremental, visto que, trouxe um melhoramento ao vagão já existente. Frisa-se, a predominância das inovações incrementais no setor ferroviário, em conformidade ao relatado por Vaz (2008).

A incorporação de novos materiais ao processo de fabricação do vagão, por sua vez, caracterizou a ecoinovação como empurrada pelo desenvolvimento tecnológico, conforme evidenciado por Rennings (2000), visto que, dedicou-se a melhorar o vagão, resultando em maior eficiência e qualidade.

Ademais, o eco-vagão trouxe conceitos de ecoinovação, corroborando os aspectos conceituais citados por Porter e Linde (1995), Rennings (2000) e Kemp e Pearson (2007), ao verificar-se que, contribuiu para a redução do impacto ambiental ocasionado pelas atividades da ferrovia. Ao mesmo tempo, agregou valor ao negócio e aos clientes, conforme exposto por Fussler e James (1996) e contribuiu para o aumento do ciclo de vida do produto e redução de recursos de fabricação, corroborando os conceitos de Reid e Miedzinski (2008) e da OECD (ORGANISATION FOR ECONOMIC CO-OPERATION AND DEVELOPMENT, 2011).

Consoante à classificação proposta por Kemp e Pearson (2007), o eco-vagão se enquadrou como uma "inovação de produto com foco em benefícios ambientais", que se assemelha à categoria "ecoinovação de produto" descrita por Bleischwitz et al. (2009). Ambas as classificações consideram a ocorrência da fabricação de um produto final melhorado e que contribui para a redução do impacto ambiental gerado pela sua produção e operação, em comparação aos métodos de produção e insumos antigos. 
No que diz respeito à Ferrovia Tereza Cristina, verificou-se que a empresa não fugiu às características do setor ferroviário. Não possui um setor responsável pela inovação, que fica a cargo dos setores de manutenção ou tecnologia de informação e utiliza recursos próprios para desenvolver seus projetos, em conformidade às características evidenciadas por Vaz (2008) e Pitassi (2011). Ademais, as suas iniciativas inovadoras, geralmente, buscam melhorias operacionais, principalmente de produtividade e redução de custos, indo ao encontro das afirmações de Fishlow (1966), Smith (2001) e Vaz (2008).

No que concerne à estratégia de inovação, a FTC adota o "posicionamento tradicional", conforme descrito por Freeman e Soete (2008). Este posicionamento é reforçado por Vaz (2008), ao descrever as características monopolísticas do segmento ferroviário de cargas, que limitam o estímulo à inovação devido a existência de um cenário próximo à concorrência perfeita.

Em contradição ao exposto por Nelson e Winter (1982) e Bessant e Tidd (2009), não foi possível evidenciar a ecoinovação como fator preponderante de competitividade na atuação da ferrovia, não havendo indícios de que o seu desenvolvimento seja um fator estratégico para a empresa. Cabe ressaltar, entretanto, que as práticas socioambientais estão incorporadas às suas políticas corporativas.

O posicionamento da empresa, em desenvolver um projeto ecoinovador voltado à sustentabilidade, permitiu classificá-la como "ecoinovadora passiva", visto que, mesmo sem possuir estratégia de inovação definida, desenvolveu um produto que resultou em ganhos ambientais, de acordo com Kemp e Pearson (2007).

Esse comportamento permitiu ainda, traçando um comparativo entre a FTC e as empresas mencionadas nos estudos que abordam a adoção de práticas ecoinovadoras, classificá-la como proativa, a exemplo das organizações estudas por Farias et al. (2012), Brito e Aguiar (2014) e Coelho (2015).

Por fim, com relação aos impactos da inovação sobre as atividades da ferrovia, foi possível observar uma série de benefícios, advindos da utilização do eco-vagão, os quais são apresentados, no Quadro 1.

Quadro 1 - Resumo dos principais benefícios observados com o eco-vagão

\begin{tabular}{|c|c|}
\hline Ambientais & Produtividade \\
\hline Utilização de materiais reciclados & Redução do tempo de descarga do carvão \\
\hline Redução do ruído no processo de descarga & Redução da perda com o transporte \\
\hline Eliminação do risco de contaminação por vazamento & Aumento da disponibilidade e da vida útil da frota \\
\hline Evita a derrubada de duas árvores por vagão & Aumento de 1,5 tonelada de carga útil por vagão \\
\hline Custos & Segurança \\
\hline Redução do custo com a produção do vagão & Aumento da confiabilidade da frota \\
\hline Redução do custo com manutenção anual & Melhoria na retenção da carga \\
\hline Redução do custo de operação & Proteção da estrutura do vagão \\
\hline Redução do custo com a revisão hexanual & Menor risco de perda de carga \\
\hline
\end{tabular}

Fonte: Dados da pesquisa (2015).

Além dos benefícios, supracitados, que englobam os domínios ambiental e econômico do desenvolvimento sustentável, pode-se apontar os benefícios sociais, advindos da implementação do projeto do eco-vagão, incorporando os três domínios da sustentabilidade mencionados pela Agenda 21 (BRASIL, 1995) e por Elkington (2004). Consequentemente, com melhores resultados econômicos, a ferrovia consegue investir em novos projetos ambientais e sociais para os colaboradores e para a comunidade local. 


\section{CONSIDERAÇÕES FINAIS}

O estudo possibilitou um diálogo entre a prática ecoinovadora desenvolvida pela empresa e àquelas analisadas pela literatura, considerando conceitos, classificações e exemplos práticos. Ademais, avançou ao explorar a temática da ecoinovação no setor ferroviário, especificamente, no segmento de transporte de cargas, que apresenta singularidade em relação ao ambiente competitivo.

Mesmo em um segmento consolidado e com característica monopolista, no qual cada operadora recebe o direito de explorar uma malha ferroviária e atua sem concorrência de outras operadoras, e sem constituir-se em determinante estratégica da empresa, foi possível perceber o papel desempenhado pela iniciativa ecoinovadora. Com o eco-vagão, a ferrovia não conquistou novos clientes ou expandiu as suas operações, mas, obteve resultados significativos com a redução dos custos e o aumento da produtividade e da confiabilidade da frota.

Ademais, o eco-vagão reduziu o impacto ambiental decorrente da operação ferroviária e fortaleceu a imagem da empresa perante a comunidade. Desse modo, o retorno obtido com o eco-vagão, ultrapassou a dimensão econômica, a qual, geralmente, limitam-se as inovações do setor, alcançando também as dimensões social e ambiental, de forma a abranger os três domínios da sustentabilidade, contribuindo assim, para a sustentabilidade da ferrovia.

Para contribuir com os debates em torno da sustentabilidade e da preservação ambiental no setor ferroviário, faz-se interessante ressaltar que a utilização de material reciclado, para a construção do eco-vagão GHD, oportuniza que outros tipos de vagões sejam construídos de forma semelhante. Para tal, faz-se necessário o interesse das empresas que atuam no setor, em investir em estudos técnicos buscando adequá-los às características das cargas transportadas.

Acrescenta-se que a indústria ferroviária vem investindo em tecnologias que reduzem os impactos ambientais, como, por exemplo, o desenvolvimento de dormentes de madeira plástica e de pisos de borracha reciclada para as passagens de nível. Essas iniciativas abrem possibilidades para novos estudos acadêmicos sobre a ecoinovação e sustentabilidade no setor ferroviário.

\section{NOTAS}

${ }^{1}$ Os vagões são classificados segundo a norma ABNT NBR 11691, na qual a primeira letra corresponde ao tipo de vagão, a segunda ao subtipo e a terceira ao peso máximo admissível e bitola. No caso do vagão GHD: Gôndola (G), com bordas basculantes ou semi-tombantes com fundo em lombo de camelo (H) e peso máximo admissível de 80 toneladas e bitola de 1,00 metro (D).

${ }^{2}$ Material resultante da movimentação e peneiramento do carvão, apresentando-se na forma de pequenas partículas.

\section{REFERÊNCIAS}

ARUNDEL, A.; KEMP, R.; PARTO, S. Indicators for environmental innovation: what and how to measure. In: MARINOVA, D.; ANNANDALE, D.; PHILLIMORE, J. (Eds.). International handbook on environment and technology management. Cheltenham: Edward Elgar, 2007. p. 324-339.

BARBIERI, J. C. et al. Inovação e sustentabilidade: novos modelos e proposições. Revista de Administração de Empresas, São Paulo, v. 50. n. 2, p. 146-154, abr./jun. 2010.

BESSANT, J.; TIDD, J. Inovação e empreendedorismo. Porto Alegre: Bookman, 2009.

BLEISCHWITZ, R. et al. Eco-innovation - putting the EU on the path to a resource and energy efficient economy. Brussels: European Parliament, 2009. 
BRASIL. Câmara dos Deputados. Conferência das Nações Unidas sobre o Meio Ambiente e Desenvolvimento: Agenda 21. Brasília: Câmara dos Deputados, 1995.

BRASIL. Lei n. 10.973, de 2 de dezembro de 2004. Diário Oficial [da] República Federativa do Brasil. Brasília, DF, 02 dez. 2004. Seção 1, p. 2-4.

BRITO, S. C.; AGUIAR, A. O. A relação entre o desenvolvimento de produtos verdes e as estratégias ambientais - o caso de uma empresa multinacional do setor de produtos eletroeletrônicos. Revista de Administração e Inovação, São Paulo, v. 11, n. 4, p. 287-309, out./dez. 2014.

COMISSÃO MUNDIAL SOBRE MEIO AMBIENTE E DESENVOLVIMENTO. Nosso futuro comum. 2. ed. Rio de Janeiro: Editora da Fundação Getúlio Vargas, 1991.

COELHO, M. A. Ecoinovação em uma pequena empresa de reciclagens da cidade de Manaus. Revista de Administração e Inovação, São Paulo, v. 12, n. 1, p. 121-147, jan./mar. 2015.

CONCEIÇÃO, O. A. C. A centralidade do conceito de inovação tecnológica no processo de mudança estrutural. Ensaios FEE, Porto Alegre, v. 21, n. 2, p. 58-76, 2000.

CONFEDERAÇÃO NACIONAL DO TRANSPORTE. O sistema ferroviário brasileiro. Brasília: Confederação Nacional do Transporte, 2013.

ELKINGTON, J. Enter the triple bottom line. In: HENRIQUES, A.; RICHARDSON, J. (Eds.). The triple bottom line, does it all add up? Assessing the sustainability of business and CSR. London: Earthscan Publications Ltd., 2004. p. 1-16.

FARIAS, A. S. et al. Utilização de eco-inovação no processo de manufatura de cerâmica vermelha. Revista de Administração e Inovação, São Paulo, v. 9, n. 3, p. 154-174, jul./set. 2012.

FERROVIA TEREZA CRISTINA. A empresa. 2015a. Disponível em: <http://ftc.com.br/a-empresa/constituicao/>. Acesso em: 25 jun. 2016.

FERROVIA TEREZA CRISTINA. Socioambiental. 2015b. Disponível em: <http://ftc.com.br/socioambiental/meioambiente/>. Acesso em: 25 jun. 2016.

FISHLOW, A. Productivity and technological change in the railroad sector, 1840-1910. In: BRADY, D. S. (Ed.). Output, employment, and productivity in the United States after 1800. New York: National Bureau of Economic Research, 1966. p. 583-646.

FREEMAN, C.; PEREZ, C. Structural crises of adjustment, business cycles and investment behaviour. In: DOSI, G. et al. (Eds.). Technical chance and economic theory. London: Pinter Publishers, 1988. p. 38-66.

FREEMAN, C.; SOETE, L. A economia da inovação industrial. Campinas: Editora Unicamp, 2008.

FREITAS, A. M. A produção de pisos de borracha e sua utilização em cruzamentos rodoferroviários. 2010. 46 f. Trabalho de Conclusão de Curso (Graduação em Engenharia de Produção) - Universidade Federal de Juiz de Fora, Minas Gerais, 2010.

FUSSLER, C.; JAMES, P. Driving eco-innovation: a breakthrough discipline for innovation and sustainability. London: Pitman Publishing, 1996.

GIL, A. C. Como elaborar projetos de pesquisa. 4. ed. São Paulo: Atlas, 2002.

KEMP, R.; PEARSON, P. Final report MEI project about measuring eco-innovation. Maastricht: UM-MERIT, 2007.

LAKATOS, E. M.; MARCONI, M. A. Fundamentos de metodologia científica. 5. ed. São Paulo: Atlas, 2003.

MAÇANEIRO, M. B. et al. Posição da empresa na cadeia produtiva do setor incidindo na adoção de estratégias de ecoinovação: um estudo na indústria brasileira de papel e celulose. In: ENCONTRO DA ASSOCIAÇÃO NACIONAL DE PÓS-GRADUAÇÃO E PESQUISA EM ADMINISTRAÇÃO, 38., 2014, Rio de Janeiro. Anais eletrônicos... Rio de Janeiro: ANPAD, 2014. Disponível em: <http://www.anpad.org.br/admin/pdf/2014_EnANPAD_GCT713.pdf>. Acesso em: 25 jun. 2016. 
NELSON, R. R.; WINTER, S. G. An evolutionary theory of economic change. Cambridge: The Belknap Press of Harvard University Press, 1982.

ORGANISATION FOR ECONOMIC CO-OPERATION AND DEVELOPMENT. Better policies to support eco-innovation. Paris: OECD Publishing, 2011. (OECD Studies on Environmental Innovation).

PARENTE, R. A.; PINHEIRO, L. M. Plásticos reciclados para elementos estruturais. Cadernos de Engenharia de Estruturas, São Carlos, v. 10, n. 47, p. 75-95, 2008.

PINSKY, V. C. et al. Inovação sustentável: uma perspectiva comparada da literatura internacional e nacional. Revista de Administração e Inovação, São Paulo, v. 12, n. 3 p. 226-250, jul./set. 2015.

PITASSI, C. O papel de um centro de P\&D em empresas de ramos tradicionais: o caso da UN de logística da Vale. Cad. Ebape.br, Rio de Janeiro, v. 9, n. 2, p. 241-261, jun. 2011.

PORTER, M. E.; LINDE, C. V. Green and competitive: ending the stalemate. Harvard Business Review, Massachusetts, v. 73, n. 5, p. 120-134, Sept./Oct. 1995.

REID, A.; MIEDZINSKI, M. Eco-innovation: final report for sectorial innovation watch. Brussels: Technopolis Group, 2008.

RENNINGS, K. Redefining Innovation - eco-innovation research and the contribution from ecological economics. Ecological Economics, v. 32, n. 2, p. 319-332, 2000.

SANTOS, D. F. L.; BASSO, L. F. C. B.; KIMURA, H. Eco-inovação na indústria sucroenergética brasileira: um estudo de caso. In: SIMPÓSIO DE ADMINISTRAÇÃO DA PRODUÇÃO, LOGÍSTICA E OPERAÇÕES INTERNACIONAIS, 17. 2014, São Paulo. Anais eletrônicos... São Paulo: FGV-EAESP, 2014. Disponível em: <http://www.simpoi.fgvsp.br/ arquivo/2014/artigos/E2014_T00235_PCN67349.pdf>. Acesso em: 25 jun. 2016.

SCHUMPETER, J. A. Teoria do desenvolvimento econômico: uma investigação sobre lucros, capital, crédito, juro e o ciclo econômico. São Paulo: Abril Cultural, 1982. (Os economistas).

SMITH, R. A. Railway technology: the last 50 years and futures prospects. Japan Railway \& Transport Review, n. 27, p. 16-24, June 2001.

THEIS, V.; SCHREIBER, D. Análise das práticas ambientais em atividades de inovação de produtos e processos. Sustentabilidade em Debate, Brasília, v. 6, n. 2, p. 155-170, mai./ago. 2015.

VAZ, A. V. A gestão da inovação tecnológica em ferrovias brasileiras de cargas. 2008. 130 f. Dissertação (Mestrado em Engenharia de Transportes) - Universidade Federal do Ceará, Fortaleza, 2008. 